Check for updates

Cite this: RSC Adv., 2018, 8, 19369

Received 13th March 2018 Accepted 17th May 2018

DOI: $10.1039 / c 8 r a 02221 f$

rsc.li/rsc-advances

\section{Graphitic-phase carbon nitride-based electrochemiluminescence sensing analyses: recent advances and perspectives}

\begin{abstract}
Jingjing Jiang, Xinyi Lin, Dong Ding and Guowang Diao (D) *
Graphitic-phase carbon nitride $\left(\mathrm{g}-\mathrm{C}_{3} \mathrm{~N}_{4}\right)$ materials are important polymeric and metal-free semiconductors, and have attracted extensive attention as emerging electrochemiluminescence (ECL) emitters due to their wonderful optical and electronic properties. The $\mathrm{g}-\mathrm{C}_{3} \mathrm{~N}_{4}$-based ECL sensing analysis, as a research hotspot in analytical chemistry, offers an exquisite pathway to monitor target analytes with the advantages of low background signal, high sensitivity, desirable controllability, and simple instrumentation. Herein, we briefly describe the current research status of $\mathrm{g}-\mathrm{C}_{3} \mathrm{~N}_{4}$-based $\mathrm{ECL}$ assays along with versatile signaling strategies, introduce the preparation methods and $\mathrm{ECL}$ emission mechanisms of $\mathrm{g}-\mathrm{C}_{3} \mathrm{~N}_{4}$-dependent emitters, summarize their ECL sensing applications from 2012 to now, highlighting with special examples of metal ion and small molecule detection, nucleic acid bioanalysis, immunoassay, protein sensing, and cell-related determination. Finally, the prospects and challenges for future work are also explored to design more advanced ECL biosensors.
\end{abstract}

\section{Introduction}

With the increasing detection demand for interesting analytes, tremendous efforts have been devoted to establishing novel and sophisticated sensing techniques in recent years, such as fluorescence, electrochemistry, colorimetry, and electrochemiluminescence (ECL), achieving significant progress in environmental monitoring, food security, and early-stage diagnosis of disease. ${ }^{1-8}$ Among them, ECL is an electrogenerated chemiluminescence process at electrode surface, in which the

School of Chemistry and Chemical Engineering, Yangzhou University, Yangzhou, Jiangsu, 225002, P. R. China. E-mail: gwdiao@yzu.edu.cn; Fax: +86-514-87975244; Tel: +86-514-87975436 excited states of emitters are generated by high-powered electron transfer reactions and then return to the ground state for light emission..$^{9-11}$ In view of the ingenious technological integration of chemiluminescence and electrochemistry, the designed ECL analysis exhibits extraordinary properties including reduced background interference, high sensitivity, desirable controllability, and low-cost equipment. ${ }^{12-18}$ For example, free of additional light source can avoid the interference of scattering light and luminescent impurities. ${ }^{19}$ Furthermore, the utilization of various emitters evidently promotes an intensive evolution for the diversity and sensitivity of ECL devices. ${ }^{20}$ Based on the universal optical and electric characteristics, some burgeoning fluorescence and

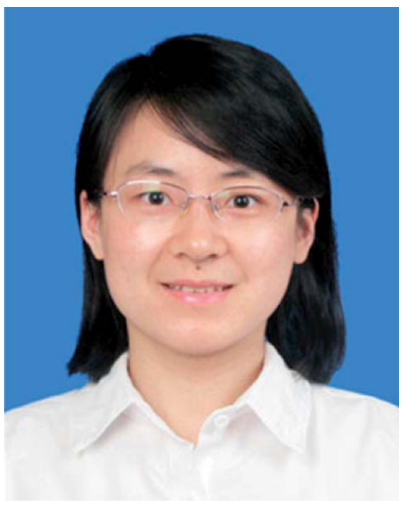

Jingjing Jiang is currently working as a lecturer at the School of Chemistry and Chemical Engineering, Yangzhou University, China. She received her BS degree in chemistry from Yangzhou University, China, in 2010 and PhD degree in chemistry from Nanjing University, China, in 2015. Her research interests are focused on the development of electrochemiluminescent and electrochemical biosensors.

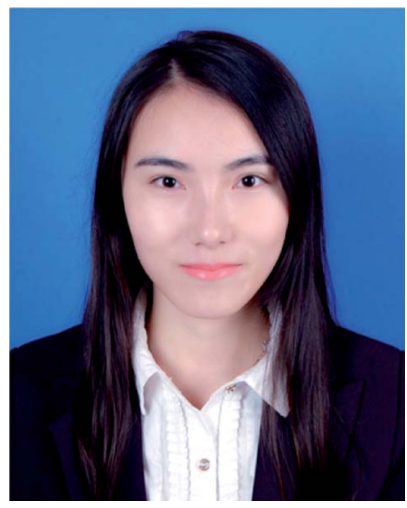

Xinyi Lin completed her BS degree in pharmaceutical engineering from Yangzhou University, China, in 2016. She is currently pursuing the MS degree at the School of Chemistry and Chemical Engineering, Yangzhou University, China. Her research interests are the preparation of nanomaterials for bioanalyses. 
photoelectrochemical active materials, especially graphene-like materials, are introduced to develop the advanced ECL detection platforms. ${ }^{21-25}$

Graphitic-phase carbon nitride $\left(\mathrm{g}-\mathrm{C}_{3} \mathrm{~N}_{4}\right)$ materials, as the crucial polymeric and metal-free semiconductors with the band gap of $2.7 \mathrm{eV}$, are mainly composed of carbon and nitrogen atoms and possess 2D graphite-like architectures with the interlamellar spacing of ca. $3.3 \mathrm{~nm} .{ }^{26-30}$ Compared with various structural forms of carbon nitride such as $\alpha-\mathrm{C}_{3} \mathrm{~N}_{4}$ and $\beta-\mathrm{C}_{3} \mathrm{~N}_{4}, \mathrm{~g}-\mathrm{C}_{3} \mathrm{~N}_{4}$ can be identified as the most stable allotrope under ambient conditions. $^{31,32}$ As shown in Fig. 1, triazine or tri-s-triazine was considered as the basic structural unit of $\mathrm{g}-\mathrm{C}_{3} \mathrm{~N}_{4} \cdot{ }^{33}$ According to the results of density functional theory, tri-s-triazine based structure exhibited higher thermal and chemical stabilities. ${ }^{34}$ Owing to the lone electron pairs of nitrogen atoms, large surface defect, and proper band gap, g- $\mathrm{C}_{3} \mathrm{~N}_{4}$ nanosheets (NTs) have been proved to be the ideal ECL emitters for the construction of sensing devices in comparison with the other carbon materials. ${ }^{35,36}$ For example, Yan et al. fabricated a solid state ECL platform based on gold nanoparticles (Au NPs) functionalized $\mathrm{g}-\mathrm{C}_{3} \mathrm{~N}_{4}$ hybrids for DNA monitoring. ${ }^{37}$ However, although some overviews concerning $g-\mathrm{C}_{3} \mathrm{~N}_{4^{-}}$ based sensing applications are reported, ${ }^{38,39}$ there has not been a special report on the ECL sensing of $\mathrm{g}-\mathrm{C}_{3} \mathrm{~N}_{4}$ until now.

Herein, we give an overview to investigate the recent progresses of $\mathrm{g}-\mathrm{C}_{3} \mathrm{~N}_{4}$-based ECL sensing analyses from 2012 to now. As shown in Fig. 2, this review will introduce the synthesis methods and ECL emission mechanisms of g- $\mathrm{C}_{3} \mathrm{~N}_{4}$-dependent emitters, summarize their sensing applications with various signal amplification strategies, which represent the significant development in this field. Finally, the unknown territory and challenges for future work are also discussed. We firmly believe that this work will be essential for interested readers to better understand their latest development status and directions.

\section{The fabrication of $\mathrm{g}-\mathrm{C}_{3} \mathrm{~N}_{4}$ materials}

In recent years, several thermal treatments, such as chemical/ physical vapor deposition, solid-state reaction, and solvothermal methods, can be used to synthesis $\mathrm{g}-\mathrm{C}_{3} \mathrm{~N}_{4}$ by
A

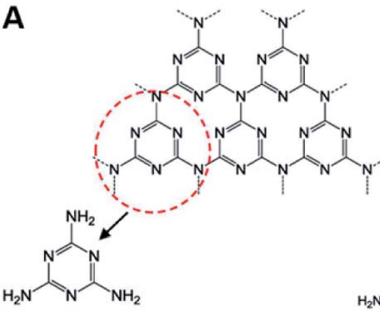

B

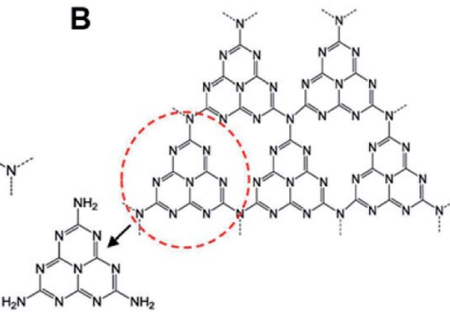

Fig. 1 (A) Triazine and (B) tri-s-triazine as the basic structural units of g- $\mathrm{C}_{3} \mathrm{~N}_{4}$. Reproduced from ref. 34 with permission from The American Chemical Society.

polymerization of various nitrogen-rich organic precursors (e.g. melamine, dicyandiamide, cyanamide, and urea) due to the strong interaction between their atomic layers. ${ }^{40-43}$ The common synthesis conditions are performed in closed or semiclosed system for the inhibition of $\mathrm{NH}_{3}$ sublimation during the condensation process. By altering the preparation conditions, $g$ $\mathrm{C}_{3} \mathrm{~N}_{4}$ with different condensation degrees are available and possess diverse physicochemical properties. ${ }^{44}$ However, the fabricated $\mathrm{g}-\mathrm{C}_{3} \mathrm{~N}_{4}$ is generally a bulk material, and the poor dispersion and low surface area largely obstruct its widespread applications in sensing fields. Due to the increasing requirement of the sophisticated ECL devices, various $\mathrm{g}-\mathrm{C}_{3} \mathrm{~N}_{4}$-based micro/nanomaterials with satisfactory water-solubility or augmented surface area (e.g. 2D nanosheets, 1D nanorods/ nanowires, and 0D quantum dots (QDs)) have attracted considerable attentions, which can be synthesized through liquid exfoliation, thermal etching, hydrothermal/solvothermal treatments, chemical tailoring, chemical oxidation, and so on. ${ }^{45-48}$ For example, Ju et al. prepared carbon nitride nanosheets (CNNS) by ultrasonic exfoliation of bulk material in water, and constructed a sensitive sensing platform for ECL detection of DNA sequence. ${ }^{49}$ Based on the low temperature solid-state approach, Lu et al. used $\mathrm{g}-\mathrm{C}_{3} \mathrm{~N}_{4}$ QDs to develop the resonance energy transfer (RET)-mediated ECL sensor for riboflavin assay. ${ }^{\mathbf{5 0}}$

To improve the determination sensitivity of constructed sensors, the functionalization of $\mathrm{g}-\mathrm{C}_{3} \mathrm{~N}_{4}$ with noble metal

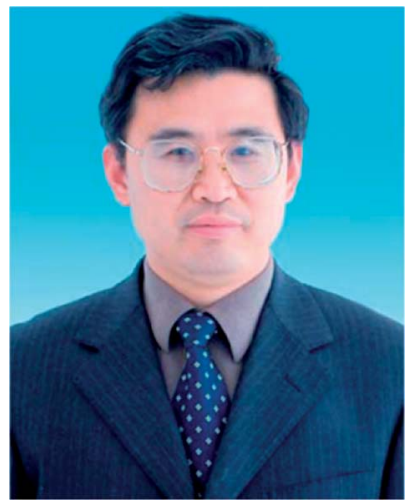

Guowang Diao received his PhD degree in analytical chemistry from Nanjing University, China, in 1997. He joined State University of $\mathrm{New}$ York, USA, as a postdoctoral research fellow from 1999 to 2001. He is a professor of Chemistry at Yangzhou University, China, and has published over 160 scientific papers. His research interests include electrochemistry-based sensors, supramolecular self-assembly, and electrochemical energy materials. 


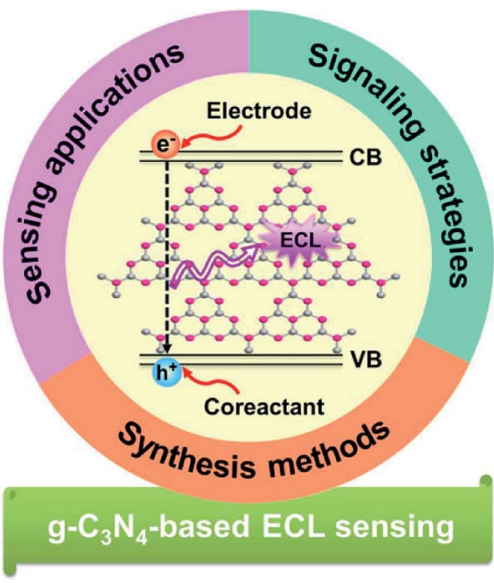

Fig. 2 Overview of $\mathrm{g}-\mathrm{C}_{3} \mathrm{~N}_{4}$-based materials for $\mathrm{ECL}$ sensing analysis.

nanoparticles, graphene, or graphene analogues have been proved to show excellent ECL performance..$^{51-53}$ Using Au NPsfunctionalized g- $\mathrm{C}_{3} \mathrm{~N}_{4}$ NTs as the ECL emitter and useful matrix for the modification of dithiobis-(succinimidyl propionate) (DSP), a desirable ECL sensor was reported for dopamine (DA) detection. ${ }^{54}$ As shown in Fig. 3, a sandwich structure sensing platform was achieved by the covalent coupling of DA molecule and 3-aminophenylboronic acid functionalized polyaniline (APBA/PANI). Based on the effective PANI-initiated ECL quenching for $\mathrm{g}-\mathrm{C}_{3} \mathrm{~N}_{4}$ NTs, this biosensor exhibited a wide linear response in the range of $0.10 \mathrm{pM}$ to $5.0 \mathrm{nM}$, as well as high selectivity depended on dual-molecule recognition approach. Furthermore, Chi's group fabricated an ECL sensor for the monitoring of folic acid (FA) using g- $\mathrm{C}_{3} \mathrm{~N}_{4}$ /reduce graphene oxide (RGO) nanohybrid. ${ }^{55}$ The introduction of RGO with $2 \mathrm{D} \pi-\pi$ conjugated framework could serve as the buffer layer for overinjected high energy electrons, and led to the stable ECL response with a declining onset potential. Taking advantage of $\mathrm{g}$ $\mathrm{C}_{3} \mathrm{~N}_{4}$ QDs decorated g- $\mathrm{C}_{3} \mathrm{~N}_{4}$ NTs, Xu et al. designed a facile ECL sensing strategy for nitrites with a detection limit down to 0.12 $\mu \mathrm{M}$. Owing to the increased surface defects, the prepared nanohybrids as luminophores exhibited preeminent ECL activities. ${ }^{56}$

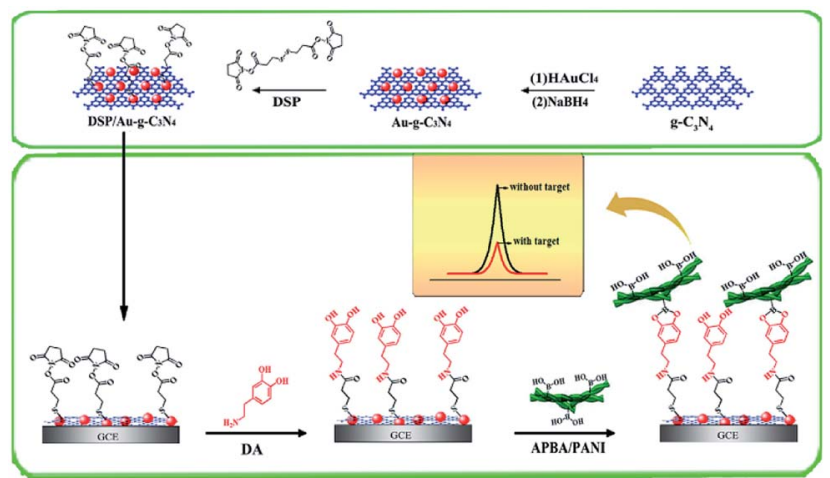

Fig. 3 The preparation of DSP-decorated Au-g- $\mathrm{C}_{3} \mathrm{~N}_{4}$ for highly selective ECL detection of DA based on dual-molecular recognition and PANI quenching. Reproduced from ref. 54 with permission from Elsevier.

\section{The $\mathrm{g}-\mathrm{C}_{3} \mathrm{~N}_{4}$-based $\mathrm{ECL}$ emission mechanisms and sensing strategies}

The emission mechanisms of luminophores are usually ascribed to the annihilation and coreactant mechanisms. ${ }^{57,58}$ In the former, the oxidized and reduced species are both generated on electrode surface during the potential sweep, and thus collide with each other to initiate ECL emission. In order to maintain the emission efficiency in the annihilation mechanism, the wide potential window and stable radical species are required. In the latter, ECL phenomenon is obtained by a single direction potential scan in the luminophore/coreactant system, in which the formed coreactant intermediate can drive the formation of the excited ECL active material under the electrochemical reduction/oxidation reaction and then the generated luminophores in the excited state return to the ground state to emit light. Compared with the annihilation mechanism, this mechanism resolves the restriction of electrochemical scanning potential range and radical stability. Thus, the improvement of emission efficiency significantly enhances the detection sensitivity in the field of ECL sensors, especially in g$\mathrm{C}_{3} \mathrm{~N}_{4}$-based ECL assays. ${ }^{59-62}$ The coreactant ECL emission mechanism can be divided into "reductive-oxidation" (R-O) ECL and "oxidative-reduction" ECL (O-R) according to the involved oxidation or reduction pathway on modified electrode surface.

In the R-O ECL mode, coreactants such as peroxydisulfate $\left(\mathrm{S}_{2} \mathrm{O}_{8}{ }^{2-}\right)$, hydrogen peroxide $\left(\mathrm{H}_{2} \mathrm{O}_{2}\right)$, and dissolved oxygen $\left(\mathrm{O}_{2}\right)$ have been widely used for the construction of $\mathrm{g}-\mathrm{C}_{3} \mathrm{~N}_{4}$-based cathodic ECL sensors. Using $\mathrm{g}-\mathrm{C}_{3} \mathrm{~N}_{4}$ nanoflake as a perfect example, Chi's group described the corresponding ECL behaviors in the presence of R-O coreactants $\left(\mathrm{S}_{2} \mathrm{O}_{8}{ }^{2-}, \mathrm{H}_{2} \mathrm{O}_{2}\right.$, and $\left.\mathrm{O}_{2}\right)$ (Fig. 4A) ${ }^{63}$ Their research indicated that the g- $\mathrm{C}_{3} \mathrm{~N}_{4}$ nanoflake film (NFF) on glassy carbon electrode (GCE) showed the intense non-surface state ECL behaviors, which could be verified by the well overlapping of ECL and fluorescence emission spectra from g- $\mathrm{C}_{3} \mathrm{~N}_{4}$ versus various wavelengths. As demonstrated in Fig. $4 \mathrm{~B}$, when the electron energy of modified electrode raised with cathodic potential polarization, the high-energy electrons were injected into the conduction band (CB) of $\mathrm{g}-\mathrm{C}_{3} \mathrm{~N}_{4} \mathrm{NFF}$ to
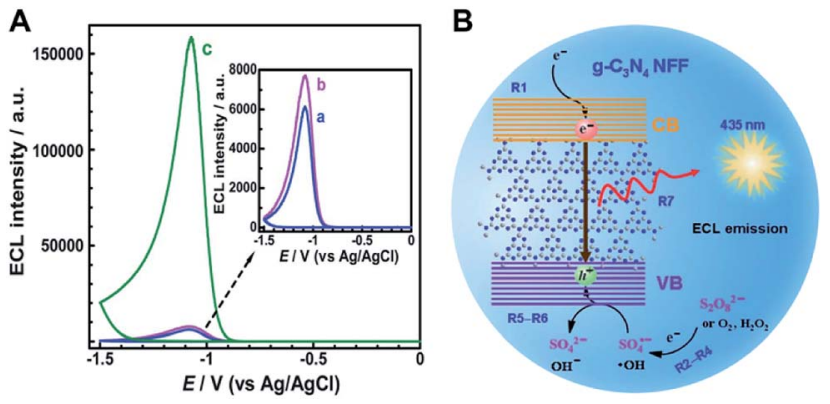

Fig. 4 (A) The ECL responses of $\mathrm{g}-\mathrm{C}_{3} \mathrm{~N}_{4}$ NFF modified GCE in $0.1 \mathrm{M}$ (a) air-saturated $\mathrm{PBS}$ of $\mathrm{pH} 7.0$, nitrogen-saturated $\mathrm{PBS}$ of $\mathrm{pH} 7.0$ containing (b) $0.258 \mathrm{mM} \mathrm{H}_{2} \mathrm{O}_{2}$ and (c) $0.258 \mathrm{mM} \mathrm{K}_{2} \mathrm{~S}_{2} \mathrm{O}_{8}$, and (B) the cathodic ECL emission mechanism for $\mathrm{g}-\mathrm{C}_{3} \mathrm{~N}_{4}$ NFF/R-O coreactant systems. Reproduced from ref. 63 with permission from The Royal Society of Chemistry. 
produce radical anions $\mathrm{g}-\mathrm{C}_{3} \mathrm{~N}_{4}{ }^{-}$(R1). Meanwhile, the hole donors (i.e. ${ }^{\circ} \mathrm{OH}$ and $\mathrm{SO}_{4}{ }^{-}$) were generated by the electrochemical reduction of the coreactants (R2-R4). After the reaction of the hole donors with $\mathrm{g}-\mathrm{C}_{3} \mathrm{~N}_{4}{ }^{-}$, the excited state $\mathrm{g}-\mathrm{C}_{3} \mathrm{~N}_{4}$ $\left(\mathrm{g}-\mathrm{C}_{3} \mathrm{~N}_{4}{ }^{*}\right)$ was formed owing to the depletion of electrons and holes in the $\mathrm{CB}$ and valence band (VB) of $\mathrm{g}-\mathrm{C}_{3} \mathrm{~N}_{4}$, respectively (R5-R6), and thus emitted blue light when they returned to their ground states.

Alternatively, we can achieve the anodic ECL in "O-R" mode. Using triethanolamine (TEA) as the O-R coreactant, Yuan et al. investigated the anodic ECL property of $\mathrm{g}-\mathrm{C}_{3} \mathrm{~N}_{4}$ modified carbon paste electrode. ${ }^{64}$ They found that a weak anodic ECL response appeared in phosphate buffer solution, while the obviously increased ECL response was observed in the presence of TEA, demonstrating the important effect of selected coreactant on the anodic ECL response. A possible ECL mechanism was reported for $\mathrm{g}-\mathrm{C}_{3} \mathrm{~N}_{4} /$ TEA system. Briefly, the positively charged $\mathrm{g}$ $\mathrm{C}_{3} \mathrm{~N}_{4}{ }^{++}$might be formed from its electrochemical oxidation when the applied voltage was more positive than the VB of $g$ $\mathrm{C}_{3} \mathrm{~N}_{4}$ during the appropriate potential scan. Similarly, TEA was electrochemically oxidized into a radical cation $\left(\mathrm{TEA}^{\cdot+}\right)$, and then decomposed to yield a powerful reductive TEA ${ }^{*}$ radical, which could react with $\mathrm{g}-\mathrm{C}_{3} \mathrm{~N}_{4}{ }^{{ }^{++}}$to form excited state $\mathrm{g}-\mathrm{C}_{3} \mathrm{~N}_{4}$ (g$\mathrm{C}_{3} \mathrm{~N}_{4}{ }^{*}$ ). After $\mathrm{g}-\mathrm{C}_{3} \mathrm{~N}_{4}$ * decayed back to its ground state, the emission light was brightened. Besides, Lei et al. found that triethylamine $\left(\mathrm{Et}_{3} \mathrm{~N}\right)$ could also enhance the anodic ECL response of $\mathrm{g}-\mathrm{C}_{3} \mathrm{~N}_{4}$ by means of the similar $\mathrm{O}-\mathrm{R}$ reaction process. ${ }^{65}$ The authors pointed out that the $\mathrm{Et}_{3} \mathrm{~N}^{\cdot}$ radical was obtained by a proton release from electro-oxidized $\mathrm{Et}_{3} \mathrm{~N}^{\cdot+}$. After reacted with $\mathrm{g}-\mathrm{C}_{3} \mathrm{~N}_{4}{ }^{++}$, the generated $\mathrm{g}-\mathrm{C}_{3} \mathrm{~N}_{4}{ }^{*}$ could trigger a strong anodic ECL signal. Zhu and coworkers developed a feasible label-free ECL aptasensor to detect acetylcholinesterase (AChE) in combination of Au NPs decorated $\mathrm{g}-\mathrm{C}_{3} \mathrm{~N}_{4}$ and TEA as luminophore and anodic coreactant, respectively. ${ }^{\mathbf{6 6}}$

Since ECL systems are generally involved in four crucial reaction steps (i.e. redox reactions on electrode surface, homogeneous chemical reactions, the generation of excited state species, and light emission), ${ }^{67}$ the ECL readouts can be regulated effectively by altering (accelerating or inhibiting) the above ECL pathways. Several ECL sensing strategies have been proposed for quantitative assays. For $\mathrm{g}-\mathrm{C}_{3} \mathrm{~N}_{4}$-based emitters, the ECL responses can be controlled by different approaches, including the introduction/separation of ECL emitters (or active species interacted with ECL emitters), the generation/ consumption of coreactants, and the steric hindrance caused by the biorecognition reaction, which directly or indirectly impact the reaction microenvironment changes via the interactions between ECL active species and the corresponding recognition events. More interestingly, in comparison with onesignal detection, the emerging dual-signal techniques are more reliable owing to the reduction of positive or negative false signals which are initiated by experimental conditions. Zhang et al. obtained dual-ECL signals of CNNS with the aid of $\mathrm{S}_{2} \mathrm{O}_{8}{ }^{2-}$ and TEA at the cathodic and anodic potentials, respectively. ${ }^{68}$ They found that the distinct quenching/enhancement effect upon diverse metal ions were realized at various driven potentials, which might result from the difference of energy level matching between CNNS and metal ions (Fig. 5A), as well as the catalytic actions of $\mathrm{CNNS}^{{ }^{+}}$and TEA $^{-}$(Fig. 5B, taking $\mathrm{Ni}^{2+}$ as a model). Thus, a potential-mediated dual-signal ECL sensor was successfully developed with no additional masking reagents and labeling, and the linear response of $\mathrm{Ni}^{2+}$ was calculated from 10 to $120 \mathrm{nM}$ with a detection limit of $2.35 \mathrm{nM}$ (Fig. 5C and D), which could significantly decrease the imperceptible false signal in comparison with the single-ECL analysis previously.

\section{Applications of $\mathrm{g}-\mathrm{C}_{3} \mathrm{~N}_{4}$-based $\mathrm{ECL}$ sensors}

As the electrogenerated chemiluminescence techniques continue to be studied, the $\mathrm{g}-\mathrm{C}_{3} \mathrm{~N}_{4}$-based ECL sensing analyses have grown rapidly, and branched out to the sensitive monitoring of various chemical/biological substances with imperative environmental and clinical significance. Here, in order to summarize their recent advances, this section is divided into five main segments including metal ion and small molecule detection, nucleic acid bioanalysis, immunoassay, protein analysis, and cell-related biosensing.

\subsection{Metal ion and small molecule detection}

As is known to all, heavy metal pollution with strong toxicity have become one of the most serious issues in our living environments, which is harmful to human health even at trace concentration level. ${ }^{69,70}$ In view of the strong adsorption capacity of $\mathrm{g}-\mathrm{C}_{3} \mathrm{~N}_{4}$ toward metal ions, ${ }^{71,72}$ several g- $\mathrm{C}_{3} \mathrm{~N}_{4}$-depended ECL
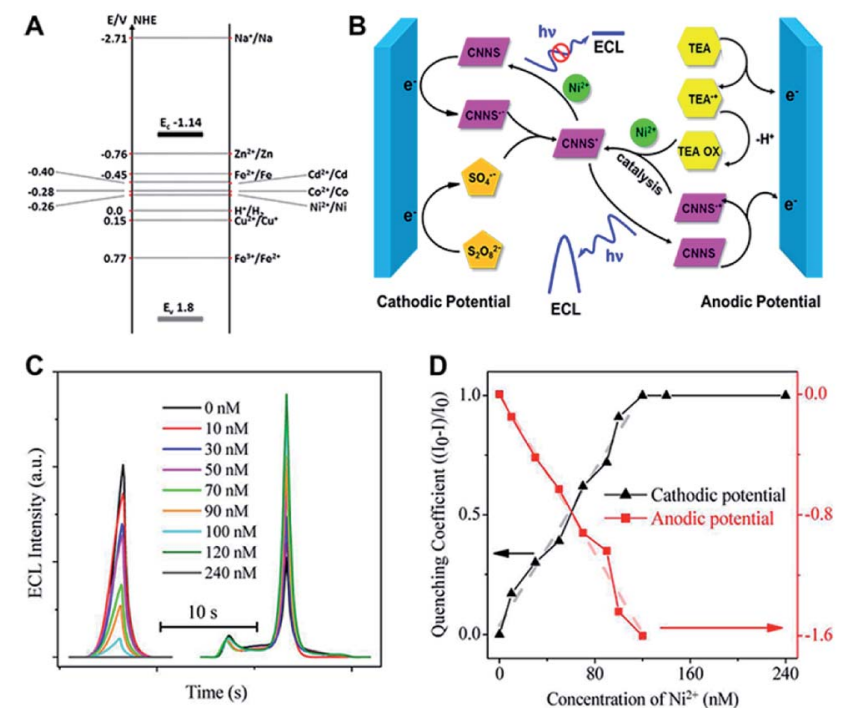

Fig. 5 (A) The electronic band structure of CNNS and oxidation/ reduction potentials of different metal ions; $(B)$ the proposed $E C L$ reaction pathways of CNNS in the presence of $\mathrm{Ni}^{2+} ;(C) \mathrm{ECL}$ intensity of CNNS-modified GCE with different $\mathrm{Ni}^{2+}$ concentrations in the presence of $\mathrm{K}_{2} \mathrm{~S}_{2} \mathrm{O}_{8}$ at cathodic potential range and TEA at anodic potential range; and (D) the linear fitting of cathodic and anodic ECL quenching coefficients. Reproduced from ref. 68 with permission from The American Chemical Society. 
sensors have been constructed for ongoing analytical requirements. For example, Xiao et al. first presented a cathodic ECL of semiconductor g- $\mathrm{C}_{3} \mathrm{~N}_{4}$ using $\mathrm{K}_{2} \mathrm{~S}_{2} \mathrm{O}_{8}$ as a coreactant. ${ }^{73}$ They found that the ECL intensity of $\mathrm{g}-\mathrm{C}_{3} \mathrm{~N}_{4}$ could be efficiently quenched through the electron transfer from $\mathrm{g}-\mathrm{C}_{3} \mathrm{~N}_{4}{ }^{-{ }^{-}}$to $\mathrm{Cu}^{2+}$, which was ascribed to the redox potential of $\mathrm{Cu}^{2+} / \mathrm{Cu}^{+}$lying between the $\mathrm{CB}$ and $\mathrm{VB}$ of $\mathrm{g}-\mathrm{C}_{3} \mathrm{~N}_{4}$ (see Fig. $5 \mathrm{~A}$ ). Consequently, a simple $\mathrm{Cu}^{2+}$ ECL sensor was developed with satisfactory linear range and low detection limit of $0.9 \mathrm{nM}$. Later, Yang's group designed a "signal-off" ECL sensor to selectively and sensitively monitor $\mathrm{Cu}^{2+}$ in the $\mathrm{g}-\mathrm{C}_{3} \mathrm{~N}_{4} /$ graphene oxide (GO) hybrid/ $\mathrm{O}_{2}$ system. ${ }^{74}$ In contrast to pure $\mathrm{g}-\mathrm{C}_{3} \mathrm{~N}_{4}$, the utilization of GO not only promoted the ECL recyclability but also achieved $380 \%$ increase of detection signal. Interestingly, based on the quenching of $\mathrm{g}-\mathrm{C}_{3} \mathrm{~N}_{4}$ NTs ECL emission by $\mathrm{Cu}^{2+}$ and the chelation of pyrophosphate ion with $\mathrm{Cu}^{2+}$, another sensitive g$\mathrm{C}_{3} \mathrm{~N}_{4}$ NTs-based ECL sensor was reported by Chi's group for the assay of pyrophosphate ion in synovial fluid. ${ }^{75}$ Moreover, Zhang et al. managed to synthesize structure-controllable CNNS for monitoring multiple metal ions. ${ }^{76}$ As demonstrated in Fig. 6A, the bulk carbon nitride $(\mathrm{CN})$ with different polymerization degree were obtained by changing the reaction temperature from 400 to $650{ }^{\circ} \mathrm{C}$, and denoted as $\mathrm{CN}-\mathrm{T}$ ( $T$ represented reaction temperature). After liquid exfoliation, the CNNS with tunable chemical structures were facilely achieved (Fig. 6C), and showed distinctive ECL responses to several metal ions (Fig. 6D). Thus, the accurate and reliable sensors were constructed due to the selective quenching resulted from electron transfer (or inner filter effect) and enhancement caused by catalytic reaction of $\mathrm{CNNS}^{{ }^{+}} / \mathrm{TEA}^{*}$ intermediates. Thus, the developed sensor showed high sensitivity for the monitoring of $\mathrm{Ni}^{2+}, \mathrm{Cd}^{2+}$ and $\mathrm{Cu}^{2+}$ with low detection limits of 1,20 , and $250 \mathrm{nM}$, respectively, and could provide an exciting and ingenious approach for the fabrication of remarkable carbon nitride family-based sensors.

The $\mathrm{g}$ - $\mathrm{C}_{3} \mathrm{~N}_{4}$-based ECL sensors were also applied for the small molecules assays. ${ }^{77,78}$ As shown in Fig. 7, Yuan et al. successfully prepared $\beta$-cyclodextrin ( $\beta$-CD) functionalized $g$ $\mathrm{C}_{3} \mathrm{~N}_{4}\left(\mathrm{~g}-\mathrm{C}_{3} \mathrm{~N}_{4}-\mathrm{CD}\right)$ as a luminophore, and then interacted with ferrocenecarboxylic acid (Fc-COOH) to form $\mathrm{g}_{-} \mathrm{C}_{3} \mathrm{~N}_{4}-\mathrm{CD}-\mathrm{Fc}-$ $\mathrm{COOH}$ inclusion complex via host-guest recognition. After acetylcholinesterase (AChE) was chemically conjugated onto inclusion complex modified electrode, a sensitive "signal-on" ECL sensor was constructed for organophosphate pesticides (OPs) determination..$^{79}$ In the absence of OPs, the hydrolysis reaction of acetylthiocholine (ATCl) by AChE could in situ
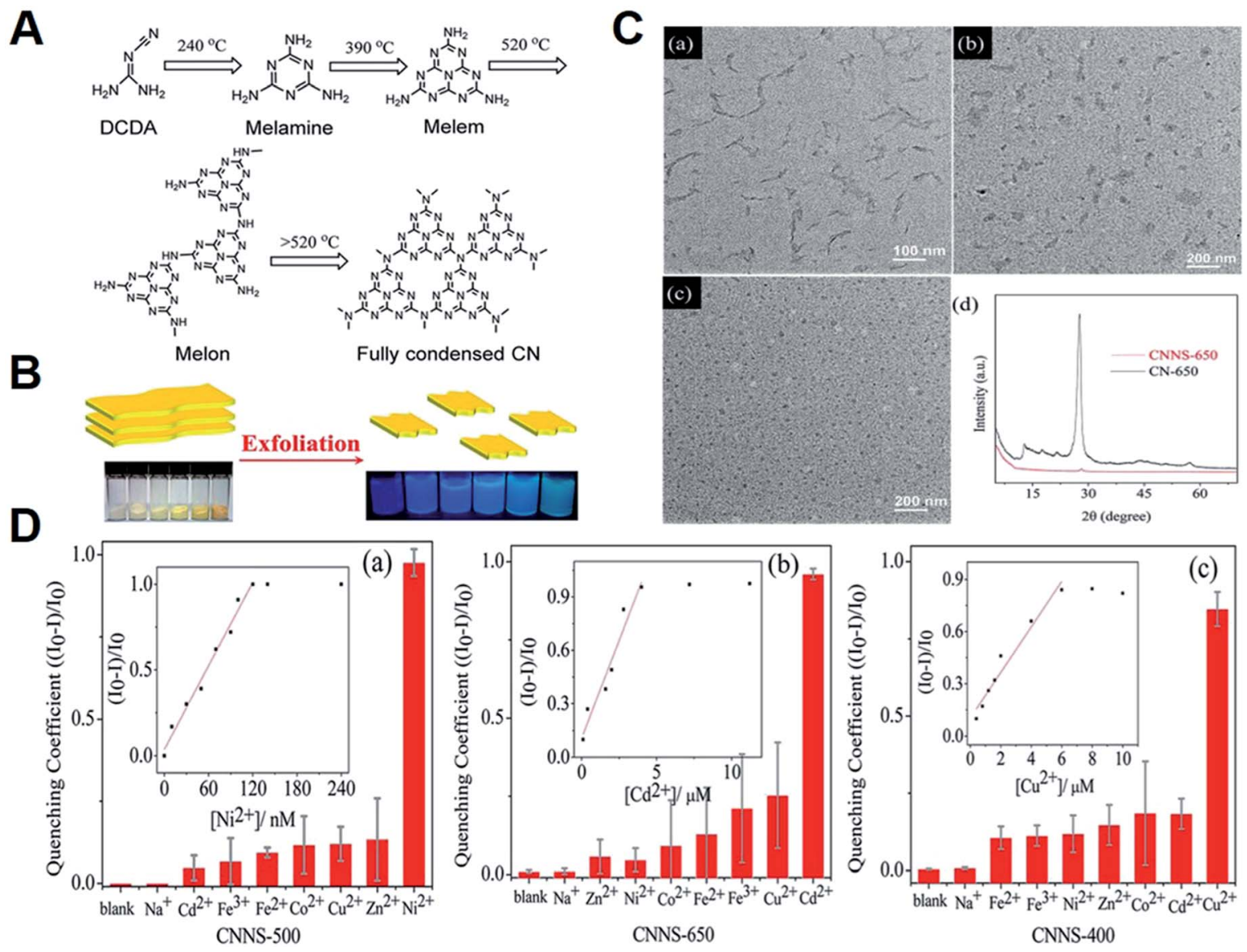

Fig. 6 (A) The typical reaction path for the formation of full condensed $C N$; (B) the process of exfoliating $C N-T(T=400,450,500,550,600$, 650); (C) TEM of (a) CNNS-400, (b) CNNS-500, and (c) CNNS-650. (d) XRD spectra of CNNS-650 and CN-650; and (D) ECL responses of (a) CNNS-500, (b) CNNS-650, and (c) CNNS-400 with various metal-ions at the cathodic potential range. Inset: calibration curves for monitoring (a) $\mathrm{Ni}^{2+}$, (b) $\mathrm{Cd}^{2+}$, and (c) $\mathrm{Cu}^{2+}$. Reproduced from ref. 76 with permission from The American Chemical Society. 
A
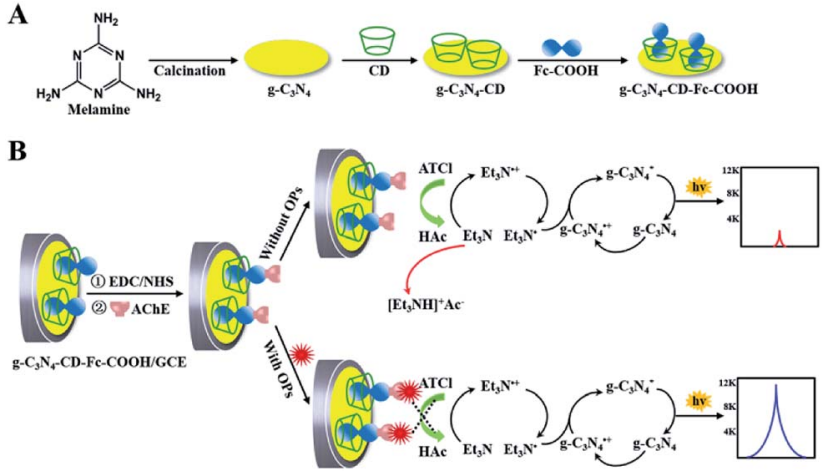

Fig. 7 (A) The synthesis procedure of $\mathrm{g}-\mathrm{C}_{3} \mathrm{~N}_{4}-\mathrm{CD}-\mathrm{Fc}-\mathrm{COOH}$. (B) Schematic diagram of the construction and response mechanism of ECL biosensor for OPs assay. Reproduced from ref. 79 with permission from The Royal Society of Chemistry.

produce acetic acid (HAc), which reacted with coreactant $\mathrm{Et}_{3} \mathrm{~N}$ to achieve a low ECL signal. However, the presence of OPs could effectively inhibit AChE activity for the lessened coreactant consumption, resulting in an enhanced ECL response. Recently, Wang et al. constructed an amplified ECL aptasensor for $17 \beta$ estradiol (E2) assay using $\mathrm{Eu}_{2} \mathrm{O}_{3} / \mathrm{g}-\mathrm{C}_{3} \mathrm{~N}_{4}$ nanocomposite as efficient luminophore. ${ }^{80}$ They found that the ECL intensity of $\mathrm{g}$ $\mathrm{C}_{3} \mathrm{~N}_{4}$ could be dramatically elevated by $\mathrm{Eu}_{2} \mathrm{O}_{3}$ clusters with oxygen vacancies. When the target was captured by $\mathrm{E} 2$ aptamer on sensing platform surface, the ECL response would decrease with the increasing E2 concentration due to the steric effect of E2-aptamer complex. Based on this, the designed ECL aptasensor manifested excellent sensitivity and selectivity toward E2. Du and coworkers developed a facile ratiometric ECL sensing for monitoring glucose levels on the basis of in situ production and conversion of coreactants triggered by the catalytic cascade reactions of glucose oxidase-immobilized g$\mathrm{C}_{3} \mathrm{~N}_{4}$-supported Au nanocomposites (GOx/Au-g-C $\mathrm{C}_{3} \mathrm{~N}_{4}$ ) (Fig. 8). ${ }^{81}$ In the absence of glucose, $\mathrm{Au}-\mathrm{g}-\mathrm{C}_{3} \mathrm{~N}_{4}$ provided a stable and strong cathodic ECL using dissolved oxygen as a coreactant.

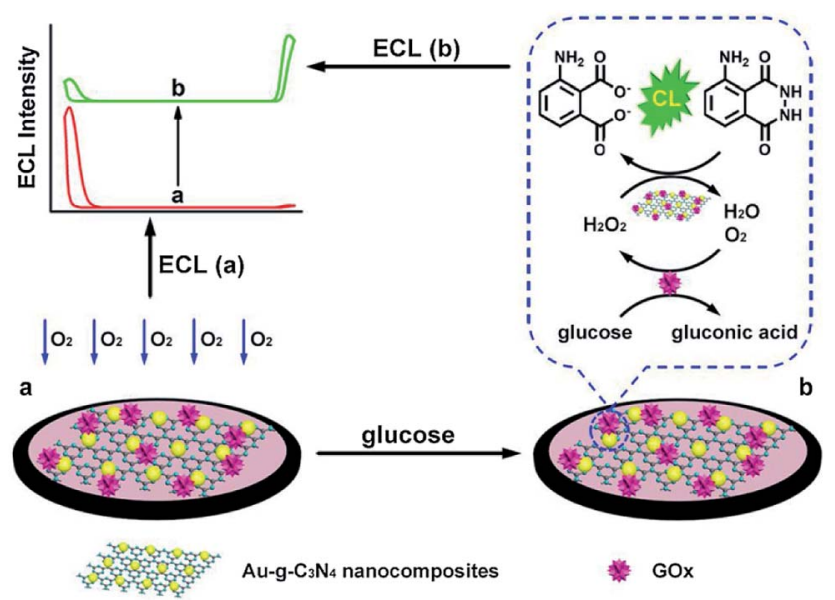

Fig. 8 The ratiometric ECL biosensor for glucose detection by means of in situ production and conversion of coreactants caused by catalytic cascade reactions of $\mathrm{GOx} / \mathrm{Au}-\mathrm{g}-\mathrm{C}_{3} \mathrm{~N}_{4}$. Reproduced from ref. 81 with permission from Elsevier.
After the addition of glucose, $\mathrm{H}_{2} \mathrm{O}_{2}$ was in situ produced by enzyme catalysis, and then converted into reactive oxygen species by Au NPs, leading to a decreased cathodic ECL from g$\mathrm{C}_{3} \mathrm{~N}_{4}$ NTs as well as an enhanced anodic ECL from luminol. By means of the competitive oxygen consumption, the designed biosensor exhibited prominent performances (such as wide linear response range, low detection limit, and high selectivity) without additional coreactants for signal amplification.

\subsection{Nucleic acid bioanalysis}

Nucleic acids are the messenger of biological genetic information and the foundation of gene expression. With the development and innovation of life science and technology, the ECL behavior of $\mathrm{g}-\mathrm{C}_{3} \mathrm{~N}_{4}$ has been widely used for nucleic acid sensing. ${ }^{82}$ For example, Shan et al. proposed an ultrasensitive ECL strategy for DNA assay coupling of the conformational conversion of biotinylated capture DNA and the favorable electrocatalytic activity of $\mathrm{g}-\mathrm{C}_{3} \mathrm{~N}_{4}$ NTs@cobalt(II) protoporphyrin IX (CoPPIX@ $\mathrm{C}_{3} \mathrm{~N}_{4}$ ) biotag. ${ }^{83}$ In the presence of target sequence, the hairpin structure of capture DNA were unfolded via biorecognition reaction and exposed the biotinylated $5^{\prime}$ extremity. Then, the streptavidin-functionalized CoPPIX@g- $\mathrm{C}_{3} \mathrm{~N}_{4}$ was immobilized on electrode interface via biotin-streptavidin linkage, and electrochemically reduced coreactant $\mathrm{H}_{2} \mathrm{O}_{2}$ for the significant decrease of ECL response. The designed biosensor could monitor target DNA down to femtomolar concentration and exhibit a wide linear range over 6 orders of magnitude. Xu's group developed a novel dualwavelength ratiometric ECL biosensor for detecting microRNA via the RET between $\mathrm{g}-\mathrm{C}_{3} \mathrm{~N}_{4}$ nanosheets and $\mathrm{Ru}(\mathrm{bpy})_{3}{ }^{2+} \cdot{ }^{84}$ As displayed in Fig. 9, the synthesized Au NPs functionalized g$\mathrm{C}_{3} \mathrm{~N}_{4}$ not only favored the modification of thiol-labeled molecular beacon, but also showed a stable ECL emission peak at $460 \mathrm{~nm}$ which matched well with the absorption peak of $\mathrm{Ru}(\mathrm{bpy})_{3}{ }^{2+}$. The spectral overlap of $\mathrm{g}-\mathrm{C}_{3} \mathrm{~N}_{4}$ NTs with Ru(bpy $)_{3}{ }^{2+}$ gave a strong evidence for the appearance of ECL emission of $\mathrm{Ru}(\mathrm{bpy})_{3}{ }^{2+}$ at $620 \mathrm{~nm}$, building a highly efficient ECL-RET system. After target microRNA hybridized with molecular beacon, the formed DNA-RNA duplex was cleaved by duplexspecific nuclease, and released microRNA to initiate the next cycle for signal enhancement. Then, the DNA-Ru(bpy) ${ }_{3}{ }^{2+}$ probe could be captured by the residual single-strand DNA on

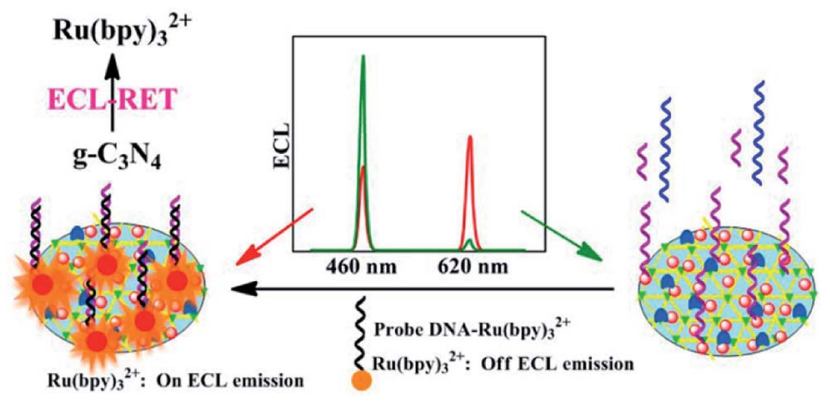

Fig. 9 Schematic diagram of a novel dual-wavelength ratiometric ECL-RET biosensor for the detection of microRNA. Reproduced from ref. 84 with permission from The American Chemical Society. 
modified electrode, leading to the decline of ECL response at $460 \mathrm{~nm}$ as well as the increase of ECL response at $620 \mathrm{~nm}$. The proposed ECL-RET method opened a new pathway for the further exploitation of dual-wavelength ECL system and exhibited potential abilities in nucleic acids bioassays.

Notably, since the properties of $\mathrm{g}^{-} \mathrm{C}_{3} \mathrm{~N}_{4}$ strongly depend on the synthesis methods, many researches have attempted to exploit new-type $\mathrm{g}-\mathrm{C}_{3} \mathrm{~N}_{4}$ with desired surface modification and functionalization. In this case, Zhang and coworkers reported that mechanical grinding of $\mathrm{CN}$ with 1-pyrenebutyrate molecules could realize the interface-modified CNNS (m-CNNS) through noncovalent exfoliation and $\pi-\pi$ stacking interactions (Fig. 10A), which not only retained the original ECL properties of CNNS material but also formed a well-assembled interface for further binding various biomolecules, shaking off the deficiencies of carbon nitride in surface science. ${ }^{85}$ Using probe ssDNA (pDNA) as a model to covalently conjugate mCNNS modified electrode, an appealing biosensor was constructed for target DNA (tDNA) detection based on the ECL quenching of $\mathrm{m}$-CNNS by $\mathrm{Cu}^{2+}$ obtained from the generation of DNA-Cu ${ }^{2+}$ complex (Fig. 10B). Instead of covalent linkage with direct physical absorption, only a small increase (9\%) was observed by the immobilization of pDNA on conventional CNNS. Thus, this ECL biosensor had enhanced sensitivity in comparison with the physical absorption of DNA probe on unmodified CNNS, and the proposed preparation method of $\mathrm{m}$ CNNS could significantly enlarge their potential application in biosensing.

\subsection{Immunoassay}

As a fascinating ECL emitter, some functionalized $\mathrm{g}-\mathrm{C}_{3} \mathrm{~N}_{4}$ nanomaterials have been applied in the construction of

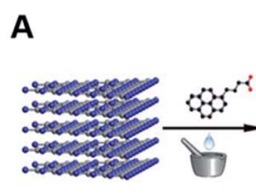

bulk CN

B
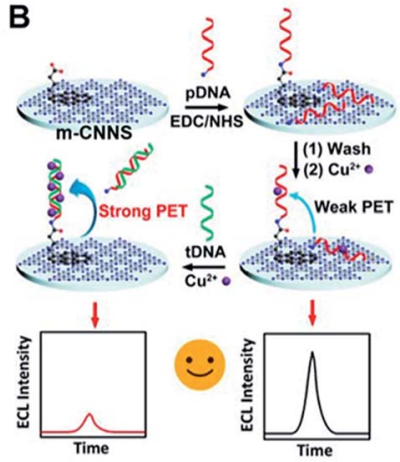

Fig. 10 (A) The general fabrication of $m$-CNNS based on simultaneous noncovalent modification and exfoliation process, and (B) the construction of ECL DNA biosensor using $\mathrm{m}-\mathrm{CNNS}$, and conventional CNNS as a control. Reproduced from ref. 85 with permission from The American Chemical Society. immunosensor with excellent detection performances. For example, Chen et al. designed an ECL immunosensor to monitor carcinoembryonic antigen (CEA) concentrations based on $\mathrm{Au}$ NPs decorated $\mathrm{g}-\mathrm{C}_{3} \mathrm{~N}_{4}$ nanohybrids. ${ }^{86}$ The introduced gold nanoparticles could effectively suppress the ECL passivation by capturing and storing the partial CB electrons of g- $\mathrm{C}_{3} \mathrm{~N}_{4}$ NTs, and catalyze the reduction of persulfate $\left(\mathrm{S}_{2} \mathrm{O}_{8}{ }^{2-}\right)$ to produce $\mathrm{SO}_{4}{ }^{-}$as hole donor, achieving a high and stable cathodic ECL response. The modified electrode was prepared by the stepwise modification of $\mathrm{Au}$ NPs functionalized $\mathrm{g}-\mathrm{C}_{3} \mathrm{~N}_{4}$ and CEA antibody (anti-CEA). After CEA was captured, the related electrons transfer and coreactant diffusion was blocked by the steric hindrance of generated protein layers, and thus the ECL response was decreased linearly from 0.02 to $80 \mathrm{ng} \mathrm{mL}{ }^{-1}$. Guo et al. constructed a disposable and label-free ECL immunosensor for the determination of carbohydrate antigen 125 (CA125) on the basis of one-off screen-printed carbon electrodes (SPCEs) and multi-functionalized g- $\mathrm{C}_{3} \mathrm{~N}_{4} \cdot{ }^{87}$ As shown in Fig. 11, the carboxylated $\mathrm{g}-\mathrm{C}_{3} \mathrm{~N}_{4}$ was sequentially functionalized by the covalent coupling of amino-coated $\mathrm{Fe}_{3} \mathrm{O}_{4}$ and CA125 antibody (anti-CA125). The introduction of $\mathrm{Fe}_{3} \mathrm{O}_{4}$ nanoparticles was beneficial to the existence of carboxylated $\mathrm{g}-\mathrm{C}_{3} \mathrm{~N}_{4}$ in the outer Helmholtz plane of biosensor and resulted in the enhancement of ECL emission of $\mathrm{g}-\mathrm{C}_{3} \mathrm{~N}_{4}$ through the accelerated electron transport between SPCEs and $\mathrm{g}-\mathrm{C}_{3} \mathrm{~N}_{4}$. After the specific binding with CA125 antibody, CA125 was captured on the sensing system, leading to the obvious inhibition of ECL response. Later, Guo et al. also developed a new potential-resolved "inelectrode" type ECL immunosensor for simultaneous monitoring of CA125 and squamous cell carcinoma antigen (SCCA) using AuNP-functionalized g- $\mathrm{C}_{3} \mathrm{~N}_{4}$ NTs as cathodic and $\mathrm{Ru}-\mathrm{NH}_{2}$ as anodic luminophores. ${ }^{88}$ In this immunoassay, the CA125 and SCCA were both captured by the corresponding anti-CA125 1 and anti-SCCA 1 , and served as join points to directly assemble the signal tags of (Ru \& anti-CA125 2 )GO and anti-SCCA 2 -AuNPs/g$\mathrm{C}_{3} \mathrm{~N}_{4}$, which showed two different ECL emissions at $1.25 \mathrm{~V}$ and $-1.3 \mathrm{~V}$, respectively. Taking advantage of the proposed strategy, the immobilized luminophores near the outer Helmholtz plane were all valid for the relevant electrochemical reactions and then produced enhanced ECL emissions. Thus, the detection

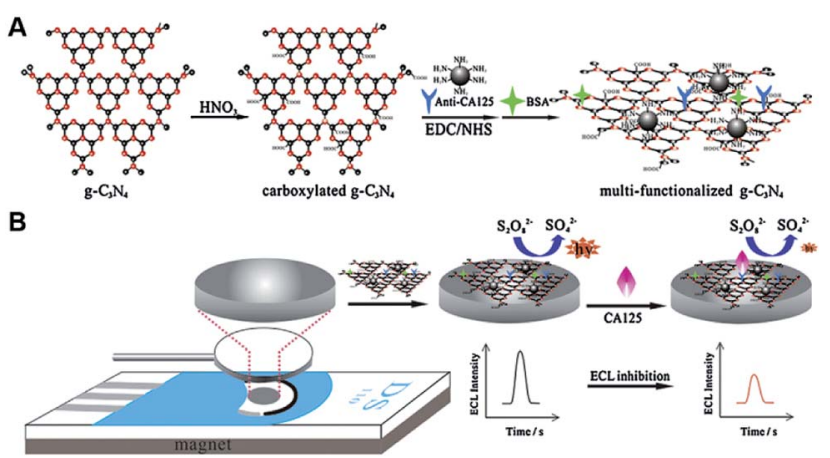

Fig. 11 Schematic illustration of $(A)$ the preparation process of multifunctionalized $\mathrm{g}-\mathrm{C}_{3} \mathrm{~N}_{4}$, and (B) the construction of proposed immunosensor for CA125 detection. Reproduced from ref. 87 with permission from Elsevier. 
limits of this immunosensor could be obtained with $0.4 \mathrm{mU}$ $\mathrm{mL}^{-1}$ for CA125 and $0.33 \mathrm{pg} \mathrm{mL}^{-1}$ for SCCA.

With the help of similar principles, $\mathrm{Li}$ and coworkers synthesized the carboxylated g- $\mathrm{C}_{3} \mathrm{~N}_{4} /$ graphene nanohybrids for ECL SCCA monitoring. ${ }^{89}$ After the deposition of $\mathrm{g}-\mathrm{C}_{3} \mathrm{~N}_{4} /$ graphene and covalent binding of anti-SCCA on the electrode surface, SCCA was captured by specific immunoreaction and impeded the diffusion of coreactant toward the electrode surface. Thus, the ECL response decreased linearly with the logarithm of SCCA concentration ranging from 0.025 to $10 \mathrm{ng}$ $\mathrm{mL}^{-1}$. Then, the authors also exploited a quenched immunosensor for the sensitive CEA determination based on Ag nanoparticles functionalized g- $\mathrm{C}_{3} \mathrm{~N}_{4}\left(\mathrm{Ag} @ g-\mathrm{C}_{3} \mathrm{~N}_{4}\right)$ as a luminophore and ferrocene carboxylic acid-labeled secondary antibody (Fc$\mathrm{COOH} @ \mathrm{Ab}_{2}$ ) as a quencher. ${ }^{90}$ In comparison with pure g- $\mathrm{C}_{3} \mathrm{~N}_{4}$, the obtained Ag@g- $\mathrm{C}_{3} \mathrm{~N}_{4}$ displayed the excellent ECL intensity and satisfactory adsorption ability, which was benefited to the assembly of primary antibody $\left(\mathrm{Ab}_{1}\right)$. Meanwhile, $\mathrm{Au}$ doped mesoporous $\mathrm{Al}_{2} \mathrm{O}_{3}$ nanorods were utilized to conjugate more Fc$\mathrm{COOH} @ \mathrm{Ab}_{2}\left(\mathrm{Au} @ \mathrm{Al}_{2} \mathrm{O}_{3}-\mathrm{Fc}-\mathrm{COOH} @ \mathrm{Ab}_{2}\right)$. After a sandwich-type immunoreaction, the ECL response decreased evidently with the increasing CEA concentration owing to the remarkable quenching effect of $\mathrm{Au} @ \mathrm{Al}_{2} \mathrm{O}_{3}-\mathrm{Fc}-\mathrm{COOH} @ \mathrm{Ab}_{2}$, which was related to the energy transfer from $\mathrm{g}-\mathrm{C}_{3} \mathrm{~N}_{4}{ }^{*}$ to ferrocenium along with the inhibition of radical reactions. Xu et al. designed a spatial-resolved ECL ratiometric device for ultrasensitive determination of prostate specific antigen (PSA) on the bipolar electrode (BPE) surface using $\mathrm{Au} @ g-\mathrm{C}_{3} \mathrm{~N}_{4}$ nanocomposites and $\mathrm{Ru}(\mathrm{bpy})_{3}{ }^{2+}$ as cathodic and anodic emitters, respectively. ${ }^{91}$ As indicated in Fig. 12, the electroneutrality of BPE ensured the electrically coupled reactions occurred on cathode and anode. Pt-polyamidoamine (PAMAM)-DNAzyme on cathode surface could quench the ECL signal of $\mathrm{g}-\mathrm{C}_{3} \mathrm{~N}_{4}$ via $\mathrm{RET}$, and promote the catalytic reduction of $\mathrm{O}_{2}$. Meanwhile, it would facilitate the ECL reaction of $\mathrm{Ru}(\mathrm{bpy})_{3}{ }^{2+}$ at anode with the increased faradaic current flowing, which was initiated by oxygen reduction. Thus, they obtained an "off-on" ECL at cathode by the release of Pt-

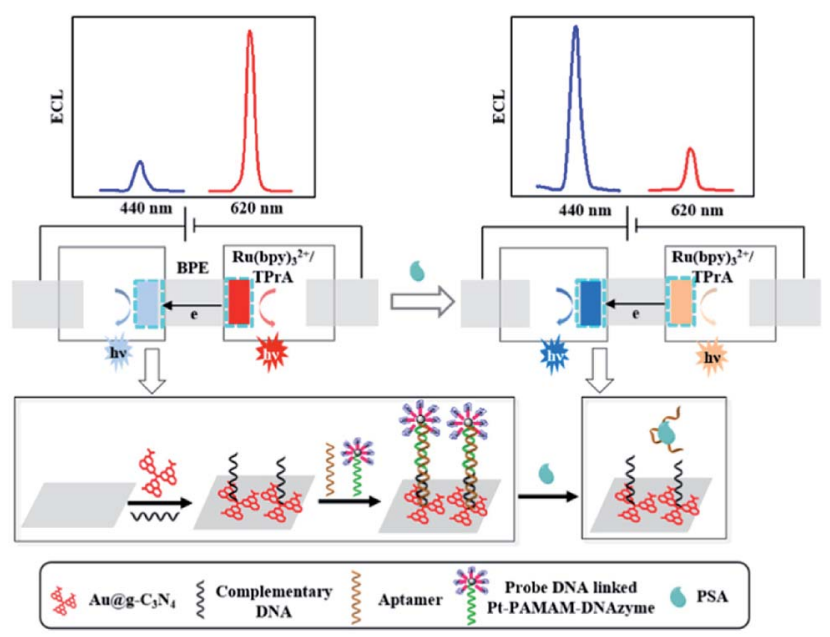

Fig. 12 The spatial-resolved ECL ratiometry for sensitive monitoring of PSA based on a closed BPE. Reproduced from ref. 91 with permission from Elsevier.
PAMAM-DNAzyme accompanied with "on-off" ECL at anode. This ratiometric biosensor for sensitive detection of PSA was achieved with a linear range from 0.10 to $200 \mathrm{ng} \mathrm{mL}^{-1}$.

\subsection{Protein analysis}

Protein molecules are key substances for composing cells and tissues in the human body, and can be also detected by g- $\mathrm{C}_{3} \mathrm{~N}_{4^{-}}$ based ECL devices. ${ }^{92}$ For instance, Kim's group deposited targetmediated polyelectrolyte-aptamer multilayer film on the solidstate modified electrode, and developed a smart permeability gate-based ECL aptasensor for bisphenol A (BPA) detection via the regulation of coreactant diffusion rate. ${ }^{93}$ As shown in Fig. 13A, the negatively charged $\mathrm{Au}-\mathrm{g}-\mathrm{C}_{3} \mathrm{~N}_{4}$ was applied onto GCE, and multiple layers of polyethyleneimine (PEI)/ polystyrene sulfonate (PSS) were deposited using layer-by-layer method, followed by the assembly of overlayered films containing PEI and BPA aptamer. Upon the addition of BPA, the formed PEI/aptamer films as a gate were destroyed through the specific binding of target molecules, resulting in the increased ECL response. Using the similar approach, they further reported a label-free ECL biosensor for sensitive determination of protease and nuclease based on target-programmable polyelectrolyte films on $\mathrm{g}-\mathrm{C}_{3} \mathrm{~N}_{4}$ modified electrode. ${ }^{94}$ Moreover, employing phenoxy dextran (DexP)-g- $\mathrm{C}_{3} \mathrm{~N}_{4}$ as signal probe, Wei et al. constructed a "signal-on" ECL sensing platform for monitoring concanavalin A (Con A). ${ }^{95}$ As shown in Fig. 13B, the prepared 3D graphene-gold nanoparticles (3D-GR-AuNPs) as an

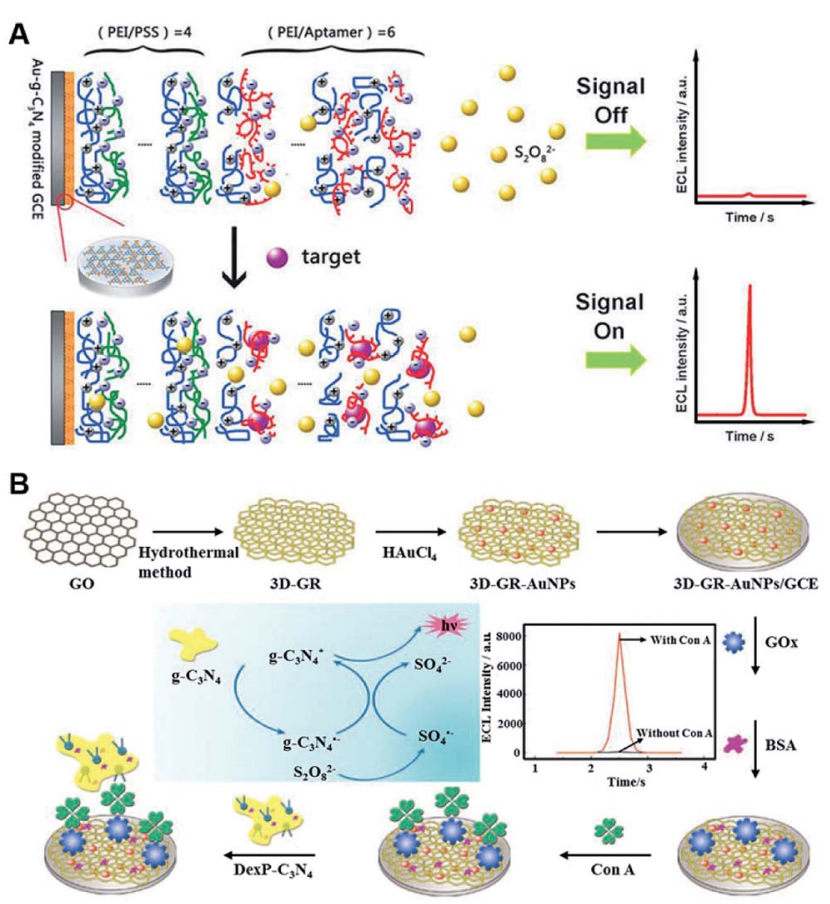

Fig. 13 Schematic illustration of (A) the novel permeability gatemediated ECL aptasensors by means of target-responsive polyelectrolyte-aptamer films (reproduced from ref. 93 with permission from The Royal Society of Chemistry), and (B) the synthetic process of 3D-GR-AuNPs for the preparation of ECL biosensor (reproduced from ref. 95 with permission from Elsevier). 
excellent matrix were utilized for GOx assembly, which could specifically recognize target Con A. After interacted with DexP$\mathrm{g}^{-} \mathrm{C}_{3} \mathrm{~N}_{4}$ by carbohydrate-Con A interaction, an enhanced ECL signal was achieved as the increase of Con A levels in the range of $0.05-100 \mathrm{ng} \mathrm{mL}^{-1}$. Subsequently, on the basis of polyaniline3,4,9,10-perylenetetracarboxylic acid-DexP conjugate (PANIPTCA-DexP) as the signal quenching probe, they developed a "signal-off" ECL biosensor for ultrasensitive Con A determination. ${ }^{96}$ The sensing platform was constructed by the sequential assembly of $\mathrm{Ag}-\mathrm{g}-\mathrm{C}_{3} \mathrm{~N}_{4}$, DexP, and GOx. Upon the anchoring of ConA, PANI-PTCA-DexP was bound onto the modified electrode and resulted in a decreased ECL response due to the quenching effect of PANI in $\mathrm{Ag}-\mathrm{g}-\mathrm{C}_{3} \mathrm{~N}_{4} / \mathrm{S}_{2} \mathrm{O}_{8}{ }^{2-}$ system. Recently, a "signal-on" aptasensor was reported by Chi's group for platelet derived growth factor (PDGF-BB) assay on the basis of $g-\mathrm{C}_{3} \mathrm{~N}_{4}$ QDs@CNNS with improved ECL activity. ${ }^{97}$ When Fc-labeled aptamer was attached, the introduced Fc could lessen the ECL signal of $\mathrm{g}-\mathrm{C}_{3} \mathrm{~N}_{4}$ QDs@CNNS at short distance. In the presence of PDGF-BB, the formed PDGF-BB/aptamer hybrid released from the luminophore surface, efficiently recovering the ECL intensity in detection system. And the ECL intensity of biosensor was proportional to PDGF-BB concentration in the range from 0.02 to $80 \mathrm{nM}$ with a detection limit down to nanomole level.

\subsection{Cell-related biosensing}

Cell is a basic unit of the organism structure and function, and the $\mathrm{g}-\mathrm{C}_{3} \mathrm{~N}_{4}$-based ECL sensing for cell-related bioanalysis has received more attention because of the great significance in human health and life science. For instance, Liu et al. built a ECL biosensor with reusable ability for cancer cells detection and their surface $\mathrm{N}$-glycan evaluation at dual-potential conditions using gold nanoparticles-modified g- $\mathrm{C}_{3} \mathrm{~N}_{4}$ as cathodic and $\mathrm{Ru}$ (phen) $)_{3}{ }^{2+}$ as anodic signal probes. ${ }^{98}$ In this work, the hybridized capture DNA/aptamer duplex DNA was immobilized onto the $\mathrm{MoS}_{2}$ NTs modified electrode, and triggered the intercalation of $\mathrm{Ru}(\text { phen })_{3}{ }^{2+}$ in its groove. By the specific interaction between the aptamer and target cells, the duplex DNA were broken into a single-strand DNA and then released the $\mathrm{Ru}(\text { phen })_{3}{ }^{2+}$. Meanwhile, a sandwich-type modified electrode was formed by the recognition interaction between mannose and Con $\mathrm{A} @ \mathrm{Au}$ NPs modified $\mathrm{g}-\mathrm{C}_{3} \mathrm{~N}_{4}$ (Con $\mathrm{A} @ \mathrm{Au}-\mathrm{C}_{3} \mathrm{~N}_{4}$ ) nanoprobe. Considering the signal ratio of cathodic and anodic ECL, this biosensor showed desirable sensitivity and selectivity, as well as avoided the traditional routing cell counting procedures. Then, Ju's group reported a similar ECL biosensor for ultrasensitive determination of circulating tumor cells (CTCs) and simultaneous evaluation of the relevant glycan expression based on CNNS and luminol-reduced Au NPs (LuAuNPs) (Fig. 14). ${ }^{99}$ The Au NPs-decorated CNNS (AuNPs@CNNS) were utilized to couple the aptamer for specific conjugation of CTCs, and lectin-functionalized LuAuNPs were used for surface glycans recognition. In the presence of MCF-7 CTCs, the decreased cathodic ECL could be attributed to the CTCs-based steric effect. Meanwhile, the anodic ECL was heightened owing to the decorated luminol molecules. Thus, this ECL
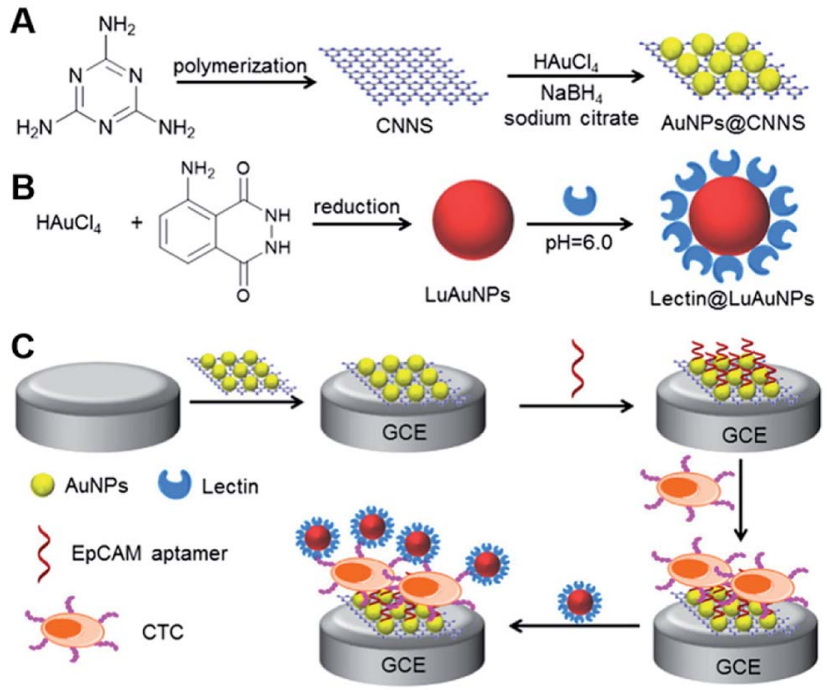

Fig. 14 The construction of a dual-potential ratiometric ECL biosensor for the monitoring CTCs and evaluating their surface glycan. Reproduced from ref. 99 with permission from Elsevier.

biosensor exhibited excellent performance for the sensitive detection of cell with a detection limit down to 2 cells, and was successfully applied for monitoring the variation of glycans on cell surface. Xu's group developed a ratiometric ECL sensing approach for HL-60 cancer cells determination using g- $\mathrm{C}_{3} \mathrm{~N}_{4}$ NTs and Ag-PAMAM-luminol nanocomposites as ECL emitters. ${ }^{100}$ DNA functionalized Ag-PAMAM-luminol nanocomposites were prepared to conjugate the aptamers on magnetic bead surfaces. After the addition of HL-60 cells, AgPAMAM-luminol nanocomposites could be liberated from magnetic bead, followed by the hybridization of capture DNA on g- $\mathrm{C}_{3} \mathrm{~N}_{4}$ modified electrode, which not only quenched the cathodic ECL of $\mathrm{g}-\mathrm{C}_{3} \mathrm{~N}_{4}$ owing to the RET originated from $\mathrm{Ag}$. NPs but also increased the anodic ECL of luminol, achieving an obvious ratio change.

\section{Conclusion and future perspectives}

In this review, we have detailed the current status of $\mathrm{g}-\mathrm{C}_{3} \mathrm{~N}_{4}$ based-ECL sensing analyses and their special applications with representative examples. Unlike the chromatographic and spectroscopic equipment, g- $\mathrm{C}_{3} \mathrm{~N}_{4}$-based ECL sensors can be easily utilized to sensitively and selectively monitor various targets including metal ions, small molecules, nucleic acids, antigens, proteins, and cells, with the features of simple instrumentation, low cost, weak background, and desirable controllability, which provide the endless driving forces for their further developments.

In-depth understanding of the signal response strategies of $\mathrm{g}-\mathrm{C}_{3} \mathrm{~N}_{4}$ materials is beneficial to the design of next-generation ECL biosensors. However, the researches of $\mathrm{g}-\mathrm{C}_{3} \mathrm{~N}_{4}$-based sensors are entering a new stage of development and facing some important issues and challenges. We believe that the 
future work will focus on the improvement of g- $\mathrm{C}_{3} \mathrm{~N}_{4}$-based ECL detection performance through the following points. Firstly, further investigate the ECL behaviors of new carbon nitride emitters (e.g. g- $\mathrm{C}_{3} \mathrm{~N}_{4}$ QDs, single layer or chemically modified g$\mathrm{C}_{3} \mathrm{~N}_{4}$ NTs) and select these g- $\mathrm{C}_{3} \mathrm{~N}_{4}$ materials with higher ECL activities. Secondly, combine $\mathrm{g}-\mathrm{C}_{3} \mathrm{~N}_{4}$ materials with new nanomaterials and biomaterials for superior sensing or biosensing. For example, dope with foreign atoms to tune the bandgap of $\mathrm{g}$ $\mathrm{C}_{3} \mathrm{~N}_{4}$ materials and increase light absorption, or hybridize with other nanomaterials to obtain an enhanced ECL response. Thirdly, by integration of several emerging techniques, the great progress and major technological breakthrough can be achieved in the near future. For example, using the $\mathrm{g}-\mathrm{C}_{3} \mathrm{~N}_{4}$ NTs modified microwell array, a novel ECL imaging strategy was proposed to simultaneously analyze total cholesterol at single cells with better visible sensitivity. ${ }^{\mathbf{1 0 1}}$ Fourthly, since most ECL sensors are only able to quantify one analyte, additional works will establish simultaneous or multiplex assay systems. Fifthly, construct reliable sensing systems for the sensitive detection of analytes in complex biological matrixes (e.g. blood, saliva, and urine). Thus, with the continual achievement of above demands, we envision that the developed $\mathrm{g}-\mathrm{C}_{3} \mathrm{~N}_{4}$-based ECL sensors can simultaneously detect different targets in complex samples using simple, rapid, and miniaturized devices, and bring tremendous influences in disease diagnosis, environmental monitoring, and biological detection.

\section{Conflicts of interest}

There are no conflicts to declare.

\section{Acknowledgements}

We gratefully acknowledge the National Natural Science Foundation of China (No. 21703199, 21773203, and 21511140282), Jiangsu Planned Projects for Postdoctoral Research Funds (No. 1601138C), and a project funded by the Priority Academic Program Development of Jiangsu Higher Education Institutions.

\section{Notes and references}

1 H. S. Jung, P. Verwilst, W. Y. Kim and J. S. Kim, Chem. Soc. Rev., 2016, 45, 1242-1256.

2 Q. F. Zhai, X. W. Zhang, Y. C. Han, J. F. Zhai, J. Li and E. K. Wang, Anal. Chem., 2016, 88, 945-951.

3 L. Krejcovaa, L. Richtera, D. Hynek, J. Labuda and V. Adama, Biosens. Bioelectron., 2017, 97, 384-399.

4 M. H. Xiang, J. W. Liu, N. Li, H. Tang, R. Q. Yu and J. H. Jiang, Nanoscale, 2016, 8, 4727-4732.

5 T. Y. Ma, Y. H. Tang, S. Dai and S. Z. Qiao, Small, 2014, 12, 2382-2389.

6 Y. Q. Yu, H. Y. Zhang, Y. Q. Chai, R. Yuan and Y. Zhou, Biosens. Bioelectron., 2016, 85, 8-15.

7 S. Su, X. Y. Han, Z. W. Lu, W. Liu, D. Zhu, J. Chao, C. H. Fan, L. H. Wang, S. P. Song, L. X. Weng and L. H. Wang, ACS Appl. Mater. Interfaces, 2017, 9, 12773-12781.
8 W. Cai, S. B. Xie, J. Zhang, D. Y. Tang and Y. Tang, Biosens. Bioelectron., 2017, 98, 466-472.

9 M. M. Richter, Chem. Rev., 2004, 104, 3003-3036.

10 J. Q. Liu, X. X. He, K. M. Wang, D. G. He, Y. H. Wang, Y. F. Mao, H. Shi and L. Wen, Biosens. Bioelectron., 2015, 70, 54-60.

11 W. W. Zhao, J. Wang, Y. C. Zhu, J. J. Xu and H. Y. Chen, Anal. Chem., 2015, 87, 9520-9531.

12 P. Zhang, Z. Y. Li, H. J. Wang, Y. Zhuo, R. Yuan and Y. Q. Chai, Nanoscale, 2017, 9, 2310-2316.

13 C. Y. Xiong, W. B. Liang, H. J. Wang, Y. N. Zheng, Y. Zhuo, Y. Q. Chai and R. Yuan, Chem. Commun., 2016, 52, 55895592.

14 X. Zhang and S. N. Ding, Biosens. Bioelectron., 2017, 94, 4755.

15 X. J. Chen, Y. He, Y. Y. Zhang, M. L. Liu, Y. Liu and J. H. Li, Nanoscale, 2014, 6, 11196-11203.

16 Y. F. Wei, H. Wang, S. J. Sun, L. F. Tang, Y. P. Cao and B. Y. Deng, Biosens. Bioelectron., 2016, 86, 714-719.

17 H. M. Chen, Q. Y. Lu, J. Y. Liao, R. Yuan and S. H. Chen, Chem. Commun., 2016, 52, 7276-7279.

18 L. Y. Zhang, D. Lia, W. L. Meng, Q. Huang, Y. Su, L. H. Wang, S. P. Song and C. H. Fan, Biosens. Bioelectron., 2009, 25, 368-372.

19 W. J. Zhu, C. Wang, X. J. Li, M. Saddam Khan, X. Sun, H. M. Ma, D. W. Fan and Q. Wei, Biosens. Bioelectron., 2017, 97, 115-121.

20 Y. Chen, S. W. Zhou, L. L. Li and J. J. Zhu, Nano Today, 2017, 12, 98-115.

21 X. M. Fu, Z. C. Gu, Q. Y. Lu, J. Y. Liao and S. H. Chen, RSC Adv., 2016, 6, 13217-13223.

22 Q. Liu, C. Ma, X. P. Liu, Y. P. Wei, C. J. Mao and J. J. Zhu, Biosens. Bioelectron., 2017, 92, 273-279.

23 M. Zhao, A. Y. Chen, D. Huang, Y. Q. Chai, Y. Zhuo and R. Yuan, Anal. Chem., 2017, 89, 8335-8342.

24 X. Ou, X. R. Tan, X. F. Liu, H. M. Chen, Y. Fan, S. H. Chen and S. P. Wei, RSC Adv., 2015, 5, 66409-66415.

25 X. Lin, S. Zhu, Q. H. Wang, Q. Xia, P. Y. Ran and Y. Z. Fu, Colloids Surf., B, 2016, 148, 371-376.

26 D. Masih, Y. Y. Ma and S. Rohani, Appl. Catal., B, 2017, 206, 556-588.

27 C. G. Gomez, A. M. Silva, M. C. Strumia, L. B. Avalle and M. I. Rojas, Nanoscale, 2017, 9, 11170-11179.

28 X. C. Wang, K. Maeda, A. Thomas, K. Takanabe, G. Xin, J. M. Carlsson, K. Domen and M. Antonietti, Nat. Mater., 2009, 8, 76-80.

29 M. Groenewolt and M. Antonietti, Adv. Mater., 2005, 17, 1789-1792.

30 E. Z. Lee, Y. S. Jun, W. H. Hong, A. Thomas and M. M. Jin, Angew. Chem., Int. Ed., 2010, 49, 9706-9710.

31 X. C. Wang, X. F. Chen, A. Thomas, X. Z. Fu and M. Antonietti, Adv. Mater., 2009, 21, 1609-1612.

32 G. Mamba and A. K. Mishra, Appl. Catal., B, 2016, 198, 347377.

33 A. Thomas, A. Fischer, F. Goettmann, M. Antonietti, J. O. Muller, R. Schlogl and J. M. Carlsson, J. Mater. Chem., 2008, 18, 4893-4908. 
34 W. J. Ong, L. L. Tan, Y. H. Ng, S. T. Yong and S. P. Chai, Chem. Rev., 2016, 116, 7159-7329.

35 Y. Wang, X. C. Wang and M. Antonietti, Angew. Chem., Int. $E d .$, 2012, 51, 68-89.

36 Y. Q. Dong, Q. Wang, H. S. Wu, Y. M. Chen, C. H. Lu, Y. W. Chi and H. H. Yang, Small, 2016, 12, 5376-5393.

37 Y. H. Wang, L. N. Zhang, L. Shen, S. G. Ge, J. H. Yu and M. Yan, Microchim. Acta, 2017, 184, 2587-2596.

38 Q. F. Zhai, J. Li and E. K. Wang, ChemElectroChem, 2017, 4, 1639-1650.

39 M. Y. Xiong, Q. M. Rong, H. M. Meng and X. B. Zhang, Biosens. Bioelectron., 2017, 89, 212-223.

40 L. C. Chen and J. B. Song, Adv. Funct. Mater., 2017, 27, 1702695.

41 K. S. Lakhi, D. H. Park, K. Al-Bahily, W. Cha, B. Viswanathan, J. H. Choy and A. Vinous, Chem. Soc. Rev., 2017, 46, 72-101.

42 Q. Zhao, W. X. Wu, X. Y. Wei, S. L. Jiang, T. Zhou, Q. Li and Q. Lu, Sens. Actuators, B, 2017, 248, 673-681.

43 B. K. Shrestha, R. Ahmad, S. Shrestha, C. H. Park and C. S. Kim, Biosens. Bioelectron., 2017, 94, 686-693.

44 Y. P. Sun, W. Ha, J. Chen, H. Y. Qi and Y. P. Shi, Trends Anal. Chem., 2016, 84, 12-21.

45 A. J. Wang, H. Li, H. Huang, Z. S. Qian and J. J. Feng, J. Mater. Chem. C, 2016, 4, 8146-8160.

46 A. W. Wang, C. D. Wang, L. Fu, W. N. Wong-Ng and Y. C. Lan, Nano-Micro Lett., 2017, 9, 47.

47 Z. X. Zhou, Y. F. Shen, Y. Li, A. R. Liu, S. Q. Liu and Y. J. Zhang, ACS Nano, 2015, 9, 12480-12487.

48 S. B. Yang, Y. J. Gong, J. S. Zhang, L. Zhan, L. L. Ma, Z. Y. Fang, R. Vajtai, X. C. Wang and P. M. Ajayan, Adv. Mater., 2013, 25, 2452-2456.

49 Y. Q. Feng, Q. B. Wang, J. P. Lei and H. X. Ju, Biosens. Bioelectron., 2015, 73, 7-12.

50 H. Wang, Q. Ma, Y. F. Wang, C. H. Wang, D. D. Qin, D. L. Shan, J. Chen and X. Q. Lu, Anal. Chim. Acta, 2017, 973, 34-42.

51 T. Q. Han, X. J. Li, Y. Y. Li, W. Cao, B. Du and Q. Wei, Sens. Actuators, B, 2014, 205, 176-183.

52 B. Y. Xia, Q. M. Yuan, M. F. Chu, S. F. Wang, R. Gao, S. L. Yang, C. B. Liu and S. L. Luo, Sens. Actuators, B, 2016, 228, 565-572.

53 L. Y. Hu, J. Zheng, K. Zhao, A. P. Deng and J. G. Li, Biosens. Bioelectron., 2018, 101, 260-267.

54 F. M. Zuo, L. Jin, X. M. Fu, H. Zhang, R. Yuan and S. H. Chen, Sens. Actuators, B, 2017, 244, 282-289.

55 C. Zhou, Y. M. Chen, P. X. Shang and Y. W. Chi, Analyst, 2016, 141, 3379-3388.

56 X. Zhu, F. X. Kou, H. F. Xu and G. D. Yang, RSC Adv., 2016, 6, 105331-105337.

57 K. Muzyka, Biosens. Bioelectron., 2014, 54, 393-407.

58 N. Hao and K. Wang, Anal. Bioanal. Chem., 2016, 408, 70357048.

59 Z. Y. Liu, W. J. Qi and G. B. Xu, Chem. Soc. Rev., 2015, 44, 3117-3142.

60 H. M. Chen, X. R. Tan, J. J. Zhang, Q. Y. Lu, X. Ou, Y. Ruo and S. H. Chen, RSC Adv., 2014, 4, 61759-61766.
61 S. D. Xie, F. Wang, Z. Y. Wu, L. Joshi and Y. Liu, RSC Adv., 2016, 6, 32804-32810.

62 Y. Zhang, L. N. Zhang, Q. K. Kong, S. G. Ge, M. Yan and J. H. Yu, Anal. Bioanal. Chem., 2016, 408, 7181-7191.

63 L. C. Chen, D. J. Huang, S. Y. Ren, T. Q. Dong, Y. W. Chi and G. N. Chen, Nanoscale, 2013, 5, 225-230.

64 C. M. Cheng, Y. Huang, J. Wang, B. Z. Zheng, H. Y. Yuan and D. Xiao, Anal. Chem., 2013, 85, 2601-2605.

65 Y. T. Liu, Q. B. Wang, J. P. Lei, Q. Hao, W. Wang and H. X. Ju, Talanta, 2014, 122, 130-134.

66 Q. Liu, Y. J. Peng, J. C. Xu, C. Ma, L. L. Li, C. J. Mao and J. J. Zhu, ChemElectroChem, 2017, 4, 1768-1774.

67 W. J. Miao, Chem. Rev., 2008, 108, 2506-2553.

68 Q. W. Shang, Z. X. Zhou, Y. F. Shen, Y. Y. Zhang, Y. Li, S. Q. Liu and Y. J. Zhang, ACS Appl. Mater. Interfaces, 2015, 7, 23672-23678.

69 B. Bansod, T. Kumar, R. Thakur, S. Rana and I. Singh, Biosens. Bioelectron., 2017, 94, 443-455.

70 P. Wu, T. Zhao, S. L. Wang and X. D. Hou, Nanoscale, 2014, 6, 43-64.

71 X. F. Chen, J. S. Zhang, X. Z. Fu, M. Antonietti and X. C. Wang, J. Am. Chem. Soc., 2009, 131, 11658-11659.

72 N. Y. Cheng, P. Jiang, Q. Liu, J. Q. Tian, A. M. Asiri and X. P. Sun, Analyst, 2014, 139, 5065-5068.

73 C. M. Cheng, Y. Huang, X. Q. Tian, B. Z. Zheng, Y. Li, H. Y. Yuan, D. Xiao, S. P. Xie and M. M. F. Choi, Anal. Chem., 2012, 84, 4754-4759.

74 B. Y. Xia, M. F. Chu, S. F. Wang, W. Q. Wang, S. L. Yang, C. B. Liu and S. L. Luo, Anal. Chim. Acta, 2015, 891, 113-119.

75 H. F. Xu, X. Zhu, Y. Q. Dong, H. S. Wu, Y. M. Chen and Y. W. Chi, Sens. Actuators, B, 2016, 236, 8-15.

76 Z. X. Zhou, Q. W. Shang, Y. F. Shen, L. Q. Zhang, Y. Y. Zhang, Y. Q. Lv, Y. Li, S. Q. Liu and Y. J. Zhang, Anal. Chem., 2016, 88, 6004-6010.

77 S. H. Chen, A. M. Li, L. Z. Zhang and J. M. Gong, Anal. Chim. Acta, 2015, 896, 68-77.

78 Y. Fan, X. R. Tan, X. F. Liu, X. Ou, S. H. Chen and S. P. Wei, Electrochim. Acta, 2015, 180, 471-478.

79 B. X. Wang, H. J. Wang, X. Zhong, Y. Q. Chai, S. H. Chen and R. Yuan, Chem. Commun., 2016, 52, 5049-5052.

80 X. J. Du, D. Jiang, L. M. Dai, W. R. Zhu, X. D. Yang, N. Hao and K. Wang, Anal. Chem., 2018, 90, 3615-3620.

81 J. J. Jiang, D. Chen and X. Z. Du, Sens. Actuators, B, 2017, 251, 256-263.

82 P. A. Rasheed, T. Radhakrishnan, S. R. Nambiar, R. T. Thomas and N. Sandhyarani, Sens. Actuators, B, 2017, 250, 162-168.

83 S. Y. Deng, P. X. Yuan, X. B. Ji, D. Shan and X. J. Zhang, ACS Appl. Mater. Interfaces, 2015, 7, 543-552.

84 Q. M. Feng, Y. Z. Shen, M. X. Li, Z. L. Zhang, W. Zhao, J. J. Xu and H. Y. Chen, Anal. Chem., 2016, 88, 937-944.

85 J. J. Ji, J. Wen, Y. F. Shen, Y. Q. Lv, Y. L. Chen, S. Q. Liu, H. B. Ma and Y. J. Zhang, J. Am. Chem. Soc., 2017, 139, 11698-11701.

86 L. C. Chen, X. T. Zeng, P. Si, Y. M. Chen, Y. W. Chi, D. H. Kim and G. N. Chen, Anal. Chem., 2014, 86, 41884195. 
87 L. Wu, Y. H. Sha, W. R. Li, S. Wang, Z. Y. Guo, J. Zhou, X. R. Su and X. H. Jiang, Sens. Actuators, B, 2016, 226, 62-68.

88 Z. Y. Guo, L. Wu, Y. F. Hu, S. Wang and X. Li, Biosens. Bioelectron., 2017, 95, 27-33.

89 X. J. Li, X. Y. Zhang, H. M. Ma, D. Wu, Y. Zhang, B. Du and Q. Wei, Biosens. Bioelectron., 2014, 55, 330-336.

90 X. J. Li, Z. K. Guo, J. X. Li, Y. Zhang, H. M. Ma, X. H. Pang, B. Du and Q. Wei, Anal. Chim. Acta, 2015, 854, 40-46.

91 Y. Z. Wang, W. Zhao, P. P. Dai, H. J. Lu, J. J. Xu, J. Pan and H. Y. Chen, Biosens. Bioelectron., 2016, 86, 683-689.

92 X. J. Li, H. M. Ma, Y. Zhang, D. Wu, X. H. Lv, B. Du and Q. Wei, Analyst, 2015, 140, 8172-8176.

93 L. C. Chen, X. T. Zeng, A. R. Ferhan, Y. W. Chi, D. H. Kim and G. N. Chen, Chem. Commun., 2015, 51, 1035-1038.

94 L. C. Chen, X. T. Zeng, A. Dandapat, Y. W. Chi and D. Kim, Anal. Chem., 2015, 87, 8851-8857.
95 X. Ou, X. R. Tan, X. F. Liu, Q. Y. Lu, S. H. Chen and S. P. Wei, Biosens. Bioelectron., 2015, 70, 89-97.

96 Y. Fan, X. R. Tan, X. Ou, Q. Y. Lu, S. H. Chen and S. P. Wei, Electrochim. Acta, 2016, 202, 90-99.

97 H. F. Xu, S. J. Liang, X. Zhu, X. Q. Wu, Y. Q. Dong, H. S. Wu, W. X. Zhang and Y. W. Chi, Biosens. Bioelectron., 2017, 92, 695-701.

98 Y. He, J. H. Li and Y. Liu, Anal. Chem., 2015, 87, 9777-9785. 99 Y. Q. Feng, F. Sun, L. Z. Chen, J. P. Lei and H. X. Ju, J. Electroanal. Chem., 2016, 781, 48-55.

100 Y. Z. Wang, N. Hao, Q. M. Feng, H. W. Shi, J. J. Xu and H. Y. Chen, Biosens. Bioelectron., 2016, 77, 76-82.

101 J. J. Xu, D. P. Jiang, Y. L. Qin, J. Xia, D. C. Jiang and H. Y. Chen, Anal. Chem., 2017, 89, 2216-2220. 